Journal of Development and Communication Studies

Vol. 4. No. 2, July 2015-June 2016 ISSN (Online \& Print): 2305-7432. bttp:/ / www.devcomsjournalmw.org. bttp://dx.doi.org/10.4314/jdcs.v4i2.5

\title{
Preferred Breast Cancer Message Sources and Frames amongst Western Kenyan Women
}

\author{
Sabina Alago, Communications Department, Great Lakes University of Kisumu, Kenya \\ \& \\ Jane Awiti, School of Communication, Languages and Performing Arts, Daystar University, Nairobi, Kenya
}

\begin{abstract}
This descriptive study set out to verify the Kenyan women's knowledge of the various risk factors associated with breast cancer, their preferred framing of the breast cancer messages and their preferred channels for receiving those messages. Three bundred and ninety-three (393) women aged 20-64 years from the Kisumu County of Western Kenya were interviewed using a semi-structured questionnaire and analysed using descriptive statistics. Findings revealed that (a) information deficiencies in relation to breast cancer is a factor that needs to be addressed, (b) gain, loss and mixed frames are used and (c) the most preferred sources of information were radio and health facility personnel and, to a low extent the internet and television. The study recommends that it is prudent for the women to voluntarily seek the right information for them to make informed decisions regarding preventive breast cancer measures. Further, cancer risk. communicators need to develop frames that revolve around symptoms and risk factors, and use the most preferred channels side by side to reinforce strengths associated with each. Internet and television among the rural women are of low use, calling for the collaborated efforts amongst development partners including the women to boost the level of their usage.
\end{abstract}

Keywords: framing messages, communication channels, breast cancer screening measures

\section{Introduction}

Breast cancer is a serious health risk/problem in Kenya and the world over (Nairobi Cancer Registry, (NCR), 2006). According to GLOBOCAN, 2012, Western Africa has a high estimated breast cancer age-standardized mortality rates $(20$ per 100,000) in comparison with other regions in the world. Breast cancer is the most common type of cancer (incidence 34 per 100,000) among Kenyan women (Kenya Network of Cancer Organizations, 2013). Breast cancer is the most frequent cause of death in low and middle-income countries, a high proportion of women suffering of breast cancer are diagnosed in the late stages of the disease (Ferlay et al., 2015).

Because breast cancer is often diagnosed in late stages, raising awareness, informing women of the risks factors to promote early detection and prevention are thus important to improve 
survival rates. Some of the known and documented risk factors include; (a) external factors, for instance, tobacco, infectious organisms, and an unhealthy diet; and (b) internal factors like inherited genetic mutations, hormones, and immune conditions (American Cancer Society (ACS), 2015). Though it is not possible to entirely prevent breast cancer related mortalities, it is possible to reduce them through preventive and detective health behavior; behaviors that are advocated for in different message frames - e.g. SBEs, CBEs, Chemotherapy (Ministry of Public Health Sanitation (MoPH), 2010; ACS, 2015).

Risk communication is one of the several preventive actions developed and organized to reduce the probability of women developing breast cancer, and/or increasing their chances of full recovery. Dransch, Rotzoll and Poser (2010) define risk communication as the process of interactively exchanging information and opinion among individuals, groups, and institutions in order to effectively reduce risks and their adverse effects. It involves multiple interactive messages on the nature of risk, concerns, opinions and/or reactions to a risk. Bottorff, Richardson, Balneaves, McCullum, Buxton, Ratner and Hack (2004) acknowledge risk communication as a vital component of risk management. Consequently, breast cancer communication effort such as message framing has been adopted to help reduce the associated incidences and mortalities.

Message framing is an important element of risk communication that needs to be considered; it is critical to place emphasis on either losses or benefits that are associated with health behaviour. Prospect theory posits that, "choices involving gains are often risks averse and choices involving losses are often risk taking" (Twersky \& Kahneman, 1981). Breast cancer communication involves creation of shared meaning and media playing massive roles in shaping and/ or reshaping perceptions and subsequent health behaviour (Parrott, 2004). Each communication process is peculiar in terms of effectiveness, specificity and impact, partly explaining the disparity in risk perceptions and health decisions (Melkote \& Steeves, 2001).

It is often a challenge to reach the women in low and middle income countries to deliver breast cancer information. Even so, risk communicators have increasingly availed breast health information to such women via multiple channels. This calls for proper channel identification and application, if expected outcomes are to be attained. Usage of multiple sources of information inescapably exposes the lay audiences to misinterpretation, misinformation, misreporting, misperceptions, inaccuracies and information deficiencies. This is because different message frames are featured and are analyzed in terms of sure or unsure gains or losses (Covello \& Peters, 2002; Carrera et al., 2010; Cohen, 2010; Keeney \& Winterfeldt, 1986; Smillie \& Blissett, 2010).

\section{Health Risk: Preventing breast cancer}

Women of all ages need to be provided with appropriate information regarding early detection measures, causes and symptoms of breast cancer. American Cancer Society (2010) notes that, women aged 20 to 24 years have the lowest incidence rate at 1.4 cases per 100,000 women. Incidence rates increase with age. The median age in which breast cancer incidences are recorded is 61 years. And as such, it recommends that; (a) women aged between 20 and 29 should perform regular Self Breast Exams (SBEs), (b) women aged between 30 and 39 should perform SBEs, as well as go for periodic Clinic Based Exams (CBEs) - after every 3 years, and (c) women aged 40 years and above should go for CBEs annually. SBEs entail examination of one's breast for any abnormalities where as CBEs entail going to a health facility for breast check-ups and cancer management. 
There is controversy regarding the efficacy of SBEs and CBEs to reduce breast cancer mortality. However, SBEs provide women the opportunity to become more familiar with their breasts. Besides, it highly contributes to early diagnosis. According to the American Cancer Society (2013, p. 2), "women should know how their breasts normally look and feel and report any breast change promptly to their health provider". The CBE is still recommended in low-income countries; this screening method may help increase breast health awareness of both, the health professionals and their patients; Anderson, Braun, Carlson, Gralow, Lagios, Lehman, Schwartsmann \& Vargas 2003). Besides, when it comes to detection of much smaller tumors, CBE is more effective notes Dey (2014).

Although mammography screening was shown to contribute to the reduction of breast cancer mortality, several disadvantages have been reported (Kosters \& Gotzsche, 2013), These authors suggest that women should be well informed of these disadvantages when invited to mammography screening. This sentiment is echoed by Jemal, Bray, Center, Ferlay, Ward, Forman (2013, p. 74), they note "although this approach is cost prohibitive and not feasible in most economically developing countries. Recommended early detection strategies in these countries include the promotion of awareness of early signs and symptoms and screening by clinical breast examination."

Bearing all these in mind, risk communicators have a challenging task of ensuring continuous framing of messages that promote awareness on signs, symptoms, preventive and detective measures amongst the vulnerable women. In this 'light', this study sought to understand what channels and what framing approaches are preferred by Kenyan women. This information will provide needed data on: (a)how to maximize women's understanding of the breast cancer disease; (b) what type of messages will help enhance the women's decision ability regarding breast health services offered in their community.

\section{Choice of channel and featured message frames}

The communication cycle consists of several important elements: 1) message, 2) channel, 3) noise, 4) recipient, 5) context, and lastly, 6 (feedback. If effective message framing is to be realized, risk communicators have to properly understand these vital elements. Baran (2009) describes the cycle as follows: The sender is the originator of the risk information, who has the task of a) conceptualizing the risk message, b) using proper symbols to encapsulate the risk message (symbols that the receiver will understand and decode accordingly), and c) choosing the right channel through which the risk message will reach the target audience. The sender of breast cancer risk messages could be public health authorities, scientists, journalists, government and other stakeholders. The recipient's functions include; receiving and decoding (interpreting) the sender's message, and giving feedback.

The present study largely focuses on two of the sender's tasks. The first concerns the conceptualization of the message, more precisely, how it should be framed to motivate women to adopt behaviors relevant to early detection and prevention of breast cancer. According to the Prospect Theory, the losses and gains perceived by individuals influence their decision process (Kahneman \& Tversky, 1979). Breast cancer risk messages just like any other health-relevant communication can be framed in two ways. The first way of framing that may be adopted is lossframing, where messages are framed in such a way that emphasis is placed on the potential losses. The second way is gain-framing where messages are framed in such a way that emphasis is placed on potential gains. The design of risk messages plays some role in influencing the attainment of the behaviour being advocated (Kahneman \& Tversky, 1979). 
The second task of the sender to be examined is choosing the right channel through which the risk message will reach the target audience. Vast media have been used to reverse the effect of breast cancer. These media include the broadcast media, print media, new media, and interpersonal media. Different media carry different messages featuring different frames, eliciting different perceptions and subsequent health behaviour. Each channel varies in terms of effectiveness, specificity and impact. Women assess messages from preferred sources, of course, with the influence of background factors they have been predisposed to.

Broadcast media such as radio and television have long and largely facilitated the effective dissemination of health messages. The new media such as the Internet are increasingly being encompassed in various health development processes. Some benefits associated with the new media include improved risk communication, improved health education, knowledge acquisition, participant mobilization and empowerment, and service exchange as well as delivery (Airhihenbuwa \& Obregon, 2000). Even so, internet services are still unavailable in most rural settings within Africa, compared to those of the advanced nations, where progress is significantly high (Adeniji, 2010). It does not necessarily mean that if such channels have been effective in one setting (western context), so will the case be in other settings. Hence the need to identify workable channels, those that are acceptable and easy to access by the target population in order to close-in on differences in women's perceptions of the proposed screening methods and subsequent health decisions.

The objectives of this study are to verify the women's knowledge of the various risks factors associated with breast cancer, the preferred framing of the preventive breast cancer messages and the preferred channels for receiving those messages. The findings will help health professionals develop needed and better adapted preventive breast cancer messages that will more effective reach Kenyan women living in rural and urban regions.

\section{Method}

The study ran from November 2012 to February 2013 in the Kisumu region of western Kenya. Subjects were selected using both random and non-random sampling techniques: stratified random sampling was used to ensure that women aged 20-64 (from both rural and urban clusters) had an equal chance of being included in the study; a purposive non-random sampling strategy was then employed to ensure that only women of required ages (between 20 and 64) were included in the study; and lastly systematic random sampling strategy helped with the inclusion of households for participation.

\section{Target population}

The study only included females because they were believed to be the most vulnerable - are more exposed to causative factors than their male counterparts. The researcher targeted women who were between 20 years and 64 years. According to ACS (2010), women aged 20 to 24 years have the lowest incidence rate at 1.4 cases per 100,000 women. Incidence rates increase with age. The median age in which breast cancer incidences are recorded is 61 years. Kenya's way of age grouping is such that each cohort has a range of 5 ages (e.g. 20-24, 30-34) and as such, the researcher assessed women between ages 20 and 64 years. In Kisumu County, there are 64, 686 females within this age bracket (KNBS, 2010). 


\section{Sample size}

To determine the sample size, Fishers et al.'s (1983) formula, as cited by Mugenda and Mugenda (1999), was used.

That is $\mathrm{n}=\left(\mathrm{z}^{2} \mathrm{p} \mathrm{q}\right) / \mathrm{d}^{2}$

where,

$\mathrm{n}=$ Minimum sample size required.

$\mathrm{p}=$ the proportion of the subjects in the target population estimated to have the characteristics being investigated - Kisumu County's population of women aged between 20 and 64. The proportion of these women is 23\% (Kenya National Bureau of Statistics (KNBS), 2010). The prevalence rate of breast cancer amongst this population being unknown, $50 \%$ was therefore used to get the sample size (Chuan, 2006).

$z=Z$ - score from the standard nominal tables. $Z_{\alpha}(\alpha$ is the significance level and is always put at 0.05 in social science $)=>Z_{0.05}=>$ usually a standard of 1.96 . $\mathrm{q}=1-\mathrm{p}$

$\mathrm{d}=$ maximum tolerable error in the study and in social science is 0.05

Where,

$\mathrm{n}=\underline{\mathrm{z}^{2} \mathrm{p} \mathrm{q}}$

$\mathrm{d}^{2}$

$z=1.96$

$\mathrm{q}=(1-0.5)$

$\mathrm{d}=0.05$

Therefore, the sample size was $=\underline{(1.96)^{2} * 0.5 *(1-0.5)}(0.05)^{2}=\underline{3.8416 * 0.5 * 0.5}$ $0.0025=384$ women.

A non-response rate of 5\% of the minimum sample was added. The final sample was 403 .

\section{Data collection and analysis}

Interviews were conducted using a semi-structured questionnaire. The first section, composed mainly of fixed choice questions, included demographic information such as age, marital status, religion, educational and economic background details. The second section included only open ended questions and aimed at obtaining the participant's opinions on breast cancer messages. It included questions in relation of their knowledge of risks factors associated with breast cancer, their preference between positively and negatively framed messages (message framing) and their preferred channels for receiving those messages. The data collection took place after acquiring the relevant permits, recruiting research assistants (RAs) and village guides, and completing a pre-test in Manyatta sub-location (urban) and Dunga sub-location (rural). During the data collection exercise 403 were initially distributed, $(10$ women withdrew, attrition rate $=2.5 \%)$ ) and a final sample of 393 women were interviewed and completed the questionnaires.

The results from the fixed answer questions were analysed using descriptive statistics; when appropriate, comparisons were made using the chi- square test. Qualitative data from the open ended questions were classified in terms of themes, analyzed, and interpreted as to appropriately 
describe and understand the women's knowledge of risk factors associated with breast cancer, their preferred between loss-framed and gain-framed preventive messages and their preferred channel.

\section{Findings}

\section{Description of Study Participants: Socio-demographic and economic profile}

A total of 393 women were interviewed, of these 90 (22.9\%) were living in rural areas while 303 (77. $20 \%$ ) were from urban clusters (Table 1: Demographic profile).

Table 1: Demographic and Socio-economic characteristics of the population $(\mathbf{N}=393)$

\begin{tabular}{|l|l|l|l|}
\hline Characteristics & $\begin{array}{l}\text { Overall } \\
\mathrm{n}(\%)\end{array}$ & $\begin{array}{l}\text { Rural } \\
\mathrm{n}(\%)\end{array}$ & $\begin{array}{l}\text { Urban } \\
\mathrm{n}(\%)\end{array}$ \\
\hline Age category & $136(34.6)$ & $13(14.4)$ & $123(40.6)$ \\
$25-24$ & $100(25.4)$ & $18(20.0)$ & $82(27.1)$ \\
$30-34$ & $56(14.2)$ & $16(17.8)$ & $40(13.2)$ \\
$35-39$ & $36(9.2)$ & $11(12.2)$ & $25(8.3)$ \\
$40-44$ & $16(4.1)$ & $8(8.9)$ & $8(2.6)$ \\
$45-49$ & $15(3.8)$ & $6(6.7)$ & $9(3.0)$ \\
$50-54$ & $14(3.6)$ & $8(8.9)$ & $6(2.0)$ \\
$55-59$ & $6(1.5)$ & $3(3.3)$ & $3(1.0)$ \\
$60-64$ & $14(3.6)$ & $7(7.8)$ & $7(2.3)$ \\
\hline Marital Status & $46(11.7)$ & $9(10.0)$ & $37(12.2)$ \\
Single & $311(79.1)$ & $67(74.4)$ & $244(80.5)$ \\
Married & $2(0.5)$ & 0 & $2(0.7)$ \\
Separated & $2(0.5)$ & 0 & $2(0.7)$ \\
Divorced & $32(8.1)$ & $14(15.6)$ & $18(5.9)$ \\
Widow & & & \\
\hline Education Level & $15(3.8)$ & $9(10.0)$ & $6(2.0)$ \\
None & $212(53.9)$ & $43(47.8)$ & $169(55.8)$ \\
Primary & $134(34.1)$ & $36(40.0)$ & $98(32.3)$ \\
Secondary & $32(8.1)$ & $2(2.2)$ & $30(9.9)$ \\
Tertiary & & & \\
\hline
\end{tabular}

The majority of those interviewed were young women, aged $20-24$ years $(34.6 \%)$. Out of this group of women, $40.6 \%(\mathrm{n}=212)$ were from urban areas. Married women accounted for $79.1 \%(311 / 393)$ while $11.7 \%(46 / 393)$ were single women. A large portion of the respondents $(53.9 \%, \mathrm{n}=212)$ had reached primary level of education and the others $(34.1 \%, \mathrm{n}=134)$ had completed the secondary level. However, the majority $(55.8 \%, \mathrm{n}=169)$ of those who had a primary education lived in the urban area while $40 \%(n=36)$ of those who reached secondary school lived in the rural clusters. A larger proportion of the respondents were self-employed (50.1\%).It is also important to mentioned that $56 \%(n=220)$ of the respondents belonged to the indigenous churches and that most of the 
respondent $(73.3 \%, \mathrm{n}=288)$ had an income level between zero and 5000 Kenyan shillings per month.

\section{Women`s knowledge of risks factors associated with breast cancer}

The messages regarding the risk factors associated with breast cancer as identified by the respondents are presented in Table 2.

Table 2: Frequency distribution on risk factors associated with of breast cancer $(\mathrm{N}=393)$

\begin{tabular}{|l|l|l|l|l|}
\hline $\begin{array}{l}\text { Reported risk factors associated } \\
\text { with breast cancer }\end{array}$ & $\begin{array}{l}\text { Overall } \\
\mathrm{N}(\%)\end{array}$ & $\begin{array}{l}\text { Rural } \\
\mathrm{n}(\%)\end{array}$ & $\begin{array}{l}\text { Urban } \\
\mathrm{n}(\%)\end{array}$ & P value \\
\hline Poor eating lifestyles & $73(22.2)$ & $54(21.5)$ & $19(24.4)$ & 0.597 \\
\hline Lack of exercises & $15(4.6)$ & $13(5.2)$ & $2(2.6)$ & 0.333 \\
\hline Inherited Cancer & $17(5.2)$ & $3(3.8)$ & $14(5.6)$ & 0.546 \\
\hline I don't know & $170(51.7)$ & $125(49.8)$ & $45(57.7)$ & 0.223 \\
\hline Poor Breast Hygiene & $26(7.9)$ & $24(9.6)$ & $2(2.6)$ & 0.0045 \\
\hline Radiation and chemicals & $3(0.9)$ & $1(0.4)$ & $2(2.6)$ & 0.079 \\
\hline Family Planning methods & $10(3.0)$ & $6(2.4)$ & $4(5.1)$ & 0.219 \\
\hline Wounds & $5(1.5)$ & $2(0.8)$ & $3(3.9)$ & 0.005 \\
\hline Total & $319(100)$ & $228(71.47)$ & $91(28.52)$ & \\
\hline
\end{tabular}

Of those interviewed, $22.2 \%(n=73)$ heard that the breast cancer is associated to poor eating lifestyles and $4.6 \%(n=15)$ were informed that breast cancer could be linked to a lack of exercises. However, the majority, $51.7 \%(n=170)$ had no idea on the main risk factors of breast cancer. There was a significant difference in proportion of rural and urban women who mentioned that they received messages on poor breast hygiene as a risk of breast cancer. The results indicate that of the $7.9 \%(n=26 / 319)$ who received this risk message, $9.6 \%(n=24 / 319)$ were living in the rural area and $2.6 \%(n=2 / 319)$ live in the urban clusters. While only $1.5 \%(n=5)$ of the risk messages were related to wounds being a risk factor, $3.9 \%$ those who got this information were from urban areas compared to only $0.8 \%$ from the rural.

\section{Framing the preventive breast cancer messages}

To understand if the messages were gain-framed or loss-framed, the respondents were asked how the messages were presented to them. Quantitative data revealed that most respondents $(n=264 / 319$; $82.08 / \%$ ) acknowledged that the messages were: positively framed, other respondents $(\mathrm{n}=55 / 31$; $17.2 \%$ ) acknowledged that the messages were negatively framed. Qualitative data supported these 
sentiments; when respondents were asked how the perceived the messaged they received in terms of framing. Majority of the responses leaned heavily on the positive framing, followed by negative framing and lastly the mixed framing as having influenced their choice of behaviour a different concern from what this paper presents.

The respondents were also asked whether they would use gain-framed or loss-framed messages to motivate other women to go for either CBEs or perform SBEs. Most of the respondents $(\mathrm{n}=55 ; 17.2 \%)$ admitted that they would use positive frames. For example, they would do this by, training and educating other women on the importance of timely breast cancer screening; telling them the symptoms; telling them the benefits of screening for breast cancer and giving right information on breast cancer detection. However, some admitted that they would use negative messages to motivate other women. For instance, telling them disadvantages of late diagnosis; telling them negative effects associated with the disease and telling them that the disease is dangerous and kills, For instance, 'I will tell them that there is a disease that kills and it's called breast cancer so please kindly go to the hospital though the money will be hard to get'.

Qualitative information revealed that some respondents do have accurate information that they would use to motivate other women to go for clinic based examination, for example, 'encouraging them to go for the test in case of abnormal lump on the breast'; 'telling them that breast cancer tends to attack breast so they should go for test'; 'talking to them in a polite way and telling them to listen to the radio to get more information'; 'giving them gifts for them to understand and telling them to go for checkups after every three months'.

\section{Channels of breast cancer risk message}

The main channels used to convey breast cancer messages are presented in Table 3.

Table 3: Channels used to deliver breast cancer messages $(\mathrm{N}=393)$

\begin{tabular}{|l|l|l|l|l|}
\hline Sources of messages & $\begin{array}{l}\text { Overall } \\
\mathrm{n}(\%)\end{array}$ & $\begin{array}{l}\text { Rural } \\
\mathrm{n}(\%)\end{array}$ & $\begin{array}{l}\text { Urban } \\
\mathrm{n}(\%)\end{array}$ & P value \\
\hline Radio & $170(48.7)$ & $45(56.2)$ & $125(46.5)$ & 0.124 \\
\hline Internet & $8(2.3)$ & $2(2.5)$ & $6(2.2)$ & 0.888 \\
\hline Television & $83(23.7)$ & $9(11.2)$ & $74(27.4)$ & 0.003 \\
\hline Health Facility Personnel & $90(25.7)$ & $21(26.2)$ & $69(25.6)$ & 0.181 \\
\hline Seminars and workshops & $30(8.6)$ & $11(13.8)$ & $19(7.0)$ & 0.060 \\
\hline Friend & $68(19.5)$ & $16(20.3)$ & $52(19.3)$ & 0.844 \\
\hline Family & $30(8.6)$ & $11(13.9)$ & $19(7.0)$ & 0.055 \\
\hline Posters & $7(2.0)$ & $2(2.5)$ & $5(1.9)$ & 0.705 \\
\hline Church & $2(0.6)$ & $1(1.3)$ & $1(0.4)$ & 0.352 \\
\hline Market Place & $1(0.3)$ & 0 & $1(0.4)$ & 0.588 \\
\hline Newspapers & $8(2.3)$ & $5(6.3)$ & $3(1.1)$ & 0.017 \\
\hline Schools & $6(1.7)$ & 0 & $6(2.2)$ & 0.181 \\
\hline Road shows & $3(0.9)$ & $2(2.5)$ & $1(0.4)$ & 0.130 \\
\hline Door-to-door campaigns & $1(0.3)$ & 0 & $1(0.4)$ & 0.588 \\
\hline Books & $2(0.6)$ & 0 & $2(0.7)$ & 0.443 \\
\hline Community Health workers & $2(0.6)$ & 0 & $2(0.7)$ & 0.443 \\
\hline
\end{tabular}


The results indicate that most of the respondents $(174 / 393 ; 48.7 \%)$ got to know about the risk factors of breast cancer through the radio. Other sources included: health facility personnel ( $90 / 393 ; 25.7 \%)$; television $(83 / 393 ; 23.7 \%)$; friends $(68 / 393 ; 19.5 \%)$; family members $(30 / 393$; $8.6 \%$ ) as well as messages from seminars and workshops (also 30/393; 8.6\%); and 2.3\% (8) . However, the result indicate that of those who received the risk messages through the TV, $11.2 \%$ of the respondents were from rural areas compared to $27.4 \%$ who live in urban. Conversely, of those who received the messages from newspapers $(6.3 \%)$ were living in rural areas compared to those living in urban areas $(1.1 \%)$.

The qualitative data revealed that: i) radio, ii) television and iii) health facility professionals were sources from which the respondents would most prefer to obtain their breast cancer messages. i)Radio was preferred because: radio sets are easily accessible (largely owned by respondents), offer credible information (guided health talks and discussions), offer locally relevant content in local language. ii). Television which uses visual content in addition to audio content, is a preferred source of breast cancer messages, for women, especially those from urban areas. The ownership of the television set and the clarity of the message were also viewed as an advantage. According to 90 respondents $(25.7 \%)$ indicating health professionals offering breast cancer education at the health facilities provide proper information, offer expertise and experiences around health issues including breast health and lastly, they health professionals ensure confidentiality of information.

Some of the respondents were not able to pick their most preferred source of breast cancer information. Some of these respondents felt that health information from any source is equally important. Others attributed their inability to settle for a preferred media to their religious background. These respondents had a strong belief in God as the creator and emphasized only Him being the healer of all diseases and they tended to associate diseases to the works of the devil. (i.e., diseases only attack evil people).

It is important to understand why internet, friends and printed channels were some of the least preferred sources of breast cancer information. Based on the feedback of respondents, internet channels are least preferred due to the inaccessibility of the internet/computer, low or limited computer literacy and operation skills, inadequate infrastructure associated with the same (e.g. electricity) and associated computer costs. Friends on the other hand are least preferred because they provide a risk of information disclosure, are not credible, that is, they may lie, spread hearsay and/or exaggerate information. The respondents dislike the printed sources because of: a lack of/ inadequate ability to read and insufficient time to read, while still others indicated it was due to lack of interest in reading the print outs.

To further understand respondents 'channels of information' choices and preferences, the respondents were asked the channels that would either motivate, or has motivated them to take up health behaviour (CBE) or SBE). According to the respondents, the channels of motivation for them to take up non-risky behaviour (e.g. SBE or CBE), include: health facility personnel for the reasons mentioned earlier and others, knowing their breast health status would motivate them to take up $\mathrm{CBE}$ or SBE. For instance, one participant responded by saying 'nikipata shida kwa matiti nitaenda' (should I have any abnormality, I will go for CBE).

Despite friends being mentioned as the least preferred source of breast cancer information, it appears to be one of the sources that would motivate a behaviour uptake in some respondents. Friends as a source of motivation is preferred by some respondents because they offer various forms of support, both material and psychological support (e.g. from one participant 'friends will console me where TV or radio haiwezi' (TV or radio cannot offer me support whereas friends will). 


\section{Discussion}

This study attempted to verify whether preventive messages have influence on Kenyan women's knowledge of risk factors associated with breast cancer and related behavioral health decisions. Persuasive messages frames (i.e., loss-framed, gain-framed and mix-framed).and the various channels utilized to deliver those messages were examined. The findings contribute to the knowledge related to risk communication by providing additional evidence that various socio-cultural and economic factors as well as the effectiveness of the type different message frames and channels must be considered when preparing and delivering preventive health messages.

\section{Demographic factors}

The results of the present study suggest that demographic factors such as age, income level, marital status, as well as social, religious and, educational backgrounds had influence on women's risk perception and health decisions. For instance, women aged 20-24 years viewing themselves as more vulnerable mainly because they were breast feeding mothers and that they were at the child bearing age, besides they confused breast cancer with mastitis, breast abscess and sore nipples. Some respondents have not gone for CBEs because they felt that it is expensive; the respondents who were very religious felt that God is the ultimate protector -the disease cannot catch up with them associated the disease with evil spirits that God cannot permit in the midst of staunch believers. These findings are in agreement with studies carried out by Cohen (2010); Bottorf et al. (2006); Leung and Leung (2010); Ko and Kim (2010); Segrin and Passalacqua (2010).

\section{Women's knowledge of risks factors}

Breast cancer messages aim at describing breast cancer, informing on breast cancer risk factors as well as reminders of screening tests available. The objective is to influence women's perceptions and their health behaviour. Change in behaviour is associated with change in perceptions. These messages revolve around breast cancer causes, symptoms and effects, as well as, mitigation measures. Even so, qualitative data reveal that most respondents did not know nor were they sure of the causes and symptoms of the disease. Such respondents however showed interest in knowing these. Some sources also provide wrong and/or deficient information on the disease, negatively influencing health decisions reached. For instance, wounds and poor breast hygiene were cited by some women as causes of breast cancer, yet they are not known causative factors. Wrong information or information deficiencies are linked to increased uptake of risky health behaviors genuine efforts geared towards wrong course, making downturn of breast cancer an ideal. These results indicate that although some accurate information is reaching the women, some are also exposed to inaccurate information or a complete lack of information.

\section{Framing breast cancer messages}

According to our results different message frames have been used to provide information regarding the detection and the prevention of breast cancer to Kenyan women. The findings from qualitative data support the three ways in which messages are framed - gain, loss and mixed framing. All three featured frames aim to elicit desired effects positive and/or negative accordingly. These frames came out clearly from the responses the women provided when they were asked how they would 
advocate for the disease to other women'; 'how respective sources would motivate them into taking up behaviour' or 'how these sources motivated them into taking up health behaviour (SBE/CBE)'. In addition, they acknowledge that the way messages are presented to them does really matter. Most of the responses that they provided revolved around messages being great reminders on positive behaviour uptake, messages being educative and informative. Other responses revolved around messages being inadequate yet the disease is pervasive, messages emphasizing on the negatives around the disease. Fewer responses revolved around message frames not being clearly formulated hence leading the women into a state of confusion.

Persuasiveness of messages is linked to proper message framing. Proper framing informs perceptions and health decisions. 'Gain-framed' messages were more effective in advocating preventive behaviors (chemotherapy, mastectomy), whereas 'loss-framed' were effective in advocating detective behaviour (CBEs, SBEs). For instance, one respondent acknowledged that use of loss frames inculcates a sense of stigma on those who are suffering from breast cancer. Message frames affect perceptions and eventually affects behaviour. These findings are in agreement with Rothman and Saloney (1997) who suggested that gain-framed messages are usually more effective than lost-framed messages for promoting health behaviors perceived to be only minimally risky to carry out. Therefore, there's need to develop messages accordingly by identifying the audience, the nature of the risk and the behaviour to be advocated. This will help in (re)shaping audience's perceptions accordingly.

\section{Message frames}

From the findings of this study some aims of the breast cancer messages are to educate the public on the disease, to inform the public on the disease and specific mitigation measures (personal or group reduction measures), to resolve controversies about the disease especially with the health facility personnel, and to act as a reminder (which has led to a state on voluntariness in positive behaviour uptake). Consequently, consenting to the take by Mattson and Basu (2010) that any course needs to "remain cognizant of the importance of messages" (p. 276). The findings are in agreement with studies by Cohen (2010); Hawkins and Linvill (2010); Kahneman and Tversky (1979); Carrera et al. (2010), showing that vast sources have indeed provided vast breast cancer messages, messages that respondents have assessed in terms of probable gains and/or losses, of course with influence of demographic factors, thus explaining different perceptions and behaviour executed by the women.

\section{Channels used to convey breast cancer messages}

Appropriate behaviour is a pointer to reception of accurate breast cancer information. In agreement with the study conducted by Bottorf et al. (2004), the finding of this study shows how sources of information other than the demographic factors influence individuals' risk estimates. Wrong or inaccurate risk perceptions have been linked to misinformation, information deficiencies and information inaccuracies (ACS, 2010). For instance, when asked about the causes of breast cancer, amongst the responses were poor breast hygiene and wounds, two unknown causative factors. The respondents largely received this information from social relations (friends, neighbours, family). Unfortunately, some of these friends would use these same messages to inform other women within their different social groupings. Eventually much effort that would go a long way in countering the effects of breast cancer is diverted as a result of inaccuracies and deficiencies in information. 
The findings of this study show that there are different sources of breast cancer information in Kenya and these can place in the three categories proposed by Baran (2009): intrapersonal, interpersonal and mass media. Broadcast media such as radio (rural and urban settings at $56.2 \%$ and $46.5 \%$ respectively) and television (27.4\% in urban) have long and are still facilitating the effective dissemination of risk messages (Adeniji, 2010; Airhihenbuwa \& Bregon, 2000; Ouma \& Herselman, 2008). Whereas radio sets are of ubiquitous presence in rural settings, messages on television sets are pervasive in urban settings. Thus the most preferred sources are specific to the settings. Even so, women are yet to optimally embrace new media in dissemination and reception of breast cancer information. New media include the internet and mobile phone technology that have picked up well in other development initiatives. The respondents listed the two amongst the least preferred sources of breast cancer information for reasons pertaining to inadequate infrastructure, literacy levels, costs (acquisition and ongoing) and language -locally relevant content. And as such, concerted efforts amongst all the stakeholders are inescapable if these barriers associated with the internet and television growth as sources of information are to be reversed.

While health facility personnel are the most preferred interpersonal channel, friends were amongst the least preferred channel. It is human nature to belong and as such, the women have their own social groupings (click of friends from different networks). It has to be noted that the women themselves are as well sources of breast cancer information. (Smillie \& Blissett, 2010; Melkote \& Steeves, 2001). Fortunately, friends as a source cannot totally be ruled off because the respondents felt that when it comes to offering different forms of support - material and emotional support, friends come in handy. Consequently when provided with right information, friends could eventually go a long way in championing this cause against breast cancer disease in terms of disseminating information as well as advocating for non-risky behaviour uptake as well us enhancing accurate information (Thompson, Dorsey, Katherine \& Parrott, 2003).

\section{Conclusion and recommendations}

The results of this study has emphasized the need to provide women with more information on cause and symptoms of breast cancer, to develop loss- framed message for detective messages and gain framed messages for preventive messages and to improve growth of internet and television usage in respective settings accordingly. The usage of broadcast media was also identified as important, especially the television and radio sets in purveying development information including health matters; frames elicit desired effects accordingly; demographic factors influence choice of channels of information. To further strengthen the breast cancer communication efforts, messages should be formulated positively and emphasis place on the risk factors and symptoms of breast cancer. The respective communicators could consider the channels that women mostly prefer such as radio, television and health facility personnel, taking into account if they live in a rural or urban region. These three types of media could also be used simultaneously to reinforce the messages and making use of their individual strengths.

Internet is a virtual space where private individuals come together to discuss, freely and rationally, all matters oriented to common good. These individuals congregate in an unrestricted manner to give meaning to symbols that they interact with as they go about their activities and thereafter arrive at a 'common' judgment. This judgment could consequently lead to transformation. And as such, concerted efforts by the government of the day and other development partners are inevitable if optimum internet use by the women around such discourses is to be attained. Not forgetting television use by the rural women, these efforts would go a long way. 
In this study, interviews were conducted using semi-structured questionnaires, however future study of a similar nature should consider utilizing the focus group technique as a principal data collection tool.

\section{References}

Adeniji, O. B. (2010).

Potentials of information and communication technologies for poverty alleviation and food security. Journal of Agricultural Extension, 14(2).

American Cancer Society. (2010).

Cancer Facts \& Figures. Atlanta: American Cancer Society; 2010.

American Cancer Society, (2013).

American Society Guidelines for Early Detection of Cancer. American Cancer Society.

American Cancer Society, (2015).

Cancer Facts \& Figures 2015. Atlanta: American Cancer Society.

Anderson, B.O., Braun, S., Carlson, R.W., Gralow, J.R., Lagios, M.D., Lehman, C., Schwartsmann, G., Vargas H,.I., (2003).

Overview of breast health care guidelines for countries with limited resources. The Breast Journal, 9 (2), 42-50.

Airhihenbuwa, C.O., Obreton, R., (2000). A critical assessment of theories/models used in health communication for HIV /AIDS. Journal of Health Communication: International Perspectives, 5 (1), 5-15. doi: $10.1080 / 10817300500119528$.

Baran, S. J. (2009).

Introduction to mass communication. Boston: McGraw Hill.

Bottorff, J. L., Richardson, C., Balneaves, L. G., McCullum, M., Buxton, J. A., Ratner, P. A., \&

Hack, T. (2004).

Unraveling women's perceptions of risk for breast cancer. Health Education Research, 19(.4), 469-475. doi: 10.1093/her/cyg050

Carrera, P., Muñoz, D., \& Caballero, A. (2010).

Mixed Emotional Appeals in Emotional and Danger Control Processes. Health Communication, 25, 726-736. doi:10.1080/10410236.2010.521914

Chua, L. (2006).

Sample size estimation using krejcie and morgan and cohen statistical power analysis: a comparison. Jurnal Penyelidikan IPBL, 7, 79-86.

Cohen, E. L. (2010).

The role of message frame, perceived risk, and ambivalence in individuals' decisions to become organ donors. Health Communication, 25 (8), 758-769. doi:10.1080/10410236.2010.521923

Covello V., \& Peters R. G. (2002).

Women's perceptions of the risks of age-related diseases, including breast cancer: reports from a 3-year research study. Health Communication, 14(3), 377-395.

Dey, S. (2014).

Preventing breast cancer in LMICs via screening and/or early detection: The real and the surreal. World Journal of Clinical Oncology, 5(3), 509-519. http//:10.5306/wjco.v5.i3.509

Dransch, D., Rotzoll, H., \& Poser, K. (2010). 
The contribution of maps to the challenges of risk communication to the public. International Journal of Digital Earth, 3(3), 292-311. www. doi: 10.1080/17538941003774668

Ferlay, J., Soerjomataram, I., Dikshit, R., Eser, S., Mathers, C., Rebelo, M., Parkin, D. M., Forman D. \& Bray, F. (2015)

Cancer incidence and mortality worldwide: Sources, methods and major patterns in

GLOBOCAN 2012. Int. J. Cancer, 136: E359-E386. doi: 10.1002/ijc.29210

GLOBOCAN, (2012).

Cancer Incidence and Mortality Worldwide: IARC Cancer Base No. 11 [nternet]. Lyon, France: International Agency for Research on Cancer; 2013. Available from http://globocan.iarc.fr.

Hawkins, K. W., \& Linvill, D. L. (2010).

Public health framing of news regarding childhood obesity in the United States, Health

Communication, 25(8), 709-717. http://doi:10.1080/10410236.2010.521913

Hortobagyi, G.N., Salazar, J.G., Pritchard, K., Lui, M.C., Martin, M., Namer, M., O’Shaughnessy,

J.A., Shen, Z.Z., Albain, K.S., ( on behalf of the ABREAST Investigators).(2005),

The Global Breast Cancer Burden: Variations in Epidemiology and Survival. Clinical Breast Cancer, 6(5), 391-401.

Jemal, A., DVM, Bray, F., Center, M., Ferlay, J., Ward \& E., Forman, D. (2011).

Global Cancer Statistics). CA CANCER J CLIN 2011; 61:69-90.

Kahneman, D., \& Tversky, A. (1979).

Prospect theory: An analysis of decision under risk. Econometrica, 47(2), 263-292.

Keeney, R., \& Winterfeldt, D. (1986).

Improving Risk Communication. Risk Analysis, 6(4), 417- 424.

Kenya National Bureau of Statistics (KNBS) and ICF Macro. (2010).

Kenya Demographic and Health Survey 2008-09. Calverton, Maryland: KNBS and ICF Macro.

Kenya National Bureau of Statistics (KNBS). (2010).

Kenya Population and Housing Census Vol-1 A and 1B:Counting our people for the implementation of vision 2030. Kenya: KNBS

Kenya Network of Cancer Organizations. (2013).

Working together to mobilize cancer awareness in Kenya! Kenya Cancer Statistics \&

National Strategies. Retrieve 19 of February, 2015 at

:https://kenyacancernetwork.wordpress.com/kenya-cancer-facts /

Ko, D., \& Kim, H. (2010.

Message framing and defensive processing: A cultural examination, Health Communication, 25:1, 61-68. doi.10.1080/10410230903473532

Kosters, J.P., Gotzsche, P.C. (2008).

Regular self-examination or clinical examination for early detection of breast cancer

(Review). The Cochrane Collaboration, issue 41.

Leung, S., \& Leung, I. (2010).

Cervical cancer screening: Knowledge, health perception and attendance rate among

HongKong Chinese women. International Journal of Women's Health, Vol. 2, 221-228.

Mattson, M., \& Basu, A. (2010).

The message development tool: a case for effective operationalization of messaging in social marketing practices'. Health Marketing Quarterly, 27(3), 275 - 290. doi:

10.1080/07359683.2010.495305

Ministry of Public Health and Sanitation. (2010). 
National Cancer Control Strategy- 2011-2016. Kenya: MoPHS.

Melkote, S. R., \& Steeves, H. L. (2001).

Communication for development in the third world ( $2^{\text {nd }}$ ed.). New Delhi, India: Sage Publications.

Mugenda, O. M., \& Mugenda, A. G. (2003).

Research methods: Quantitative and qualitative approaches. Nairobi, Kenya: ACTS.

Nairobi Cancer Registry. (2006).

Retrieved February 15, 2012 from:

http://marsgroupkenya.org/pdfs/2011/01/Ministry PDFS/Ministry of Public Health an d Sanitation/REPORTS/Cancer Incidence Report 2006 KEMRI.pdf.

Ouma, S., \& Herselman, M. E. (2008).

E- health in rural areas: Case of developing countries. International Journal of Biological and Life

Sciences. 4(4), 194-200.

Parrott, R. (2004).

Emphasizing "communication" in health communication. Journal of Communication, 54(4), 751-787. doi: 10.1111/j.1460-2466.2004.tb02653.x

Rothman, A.J., \& Salovey, P. (1997).

Sharpening perceptions to motivate healthy behaviour: The role of message framing.

Psychological Bulletin, 121, 3-19.

Segrin, C., \& Passalacqua, S. (2010)

Functions of loneliness, social support, health behaviors, and stress in association with poor health, Health Communication, 25(4), 312-322. doi.10.1080/10410231003773334

Smillie, L., \& Blissett, A. (2010): A model for developing risk communication strategy. Journal of Risk

Research, 13(1), 115-134. doi10.1080/13669870903503655

Story, H., Love, R., Salim, R., Roberto, A., Krieger, J., \& Ginsburg, O. (2012).

Improving Outcomes from Breast Cancer in a Low-Income Country: Lessons from

Bangladesh, International Journal of Breast Cancer, vol. 2012, Article ID 423562, 9 pages, 2012. doi:10.1155/2012/423562

Tversky, A., \& Kahneman, D.(1981).

The framing of decisions and the psychology of choice. Science, 211, 453-458.

Thompson, T., L., Dorsey, A., Miller, K., \& Parrott, R. (2003).

Social support, social networks and health. In T.L. Albrecht \& D.J. Goldsmith (eds.), Handbook of

bealth communication, (pp.263-284). US: Lawrence Elbaum Associates, Inc. 